\title{
Autoimmune Hemolytic Anemia in a Patient with Acute Myelomonocytic Leukemia
}

Noha Essa, Shaimaa El-Ashwah, May Denewer, Yasmine Essam and Mohamed Mabed

Division of Hematology, Oncology Center, Mansoura University, Egypt

"Corresponding author: Mohamed Mabed, MD, PhD, Division of Hematology, Oncology Center, Faculty of Medicine, Mansoura University, Egypt, Tel: 00201068595165; Fax: 002050 2370103; E-mail: mohmabed@mans.edu.eg

Received date: Dec 17, 2015, Accepted date: Jan 19, 2016, Publication date: Jan 22, 2016

Copyright: ( 2016 Essa N, et al. This is an open-access article distributed under the terms of the Creative Commons Attribution License, which permits unrestricted use, distribution, and reproduction in any medium, provided the original author and source are credited.

\begin{abstract}
Autoimmune hemolytic anemia (AlHA) has been described in patients with lymphoid neoplasm with an etiologic relationship between the emergence of autoantibodies and lymphocyte dysfunction. Autoimmune disorders are less to develop in patients with other neoplasm like chronic myeloid leukemia, myelodysplastic syndrome or acute myeloid leukemia. Few reports have been documented the development of immune hemolytic anemia in patients with acute myeloid leukemia. We herein, present the case of de novo acute myelomonocytic leukemia associated with autoimmune hemolytic anemia. The patient has no previous medical history of anemia and $\mathrm{Hb}$ level at presentation was normal. She received chemotherapy containing Adriamycin plus Cytarabine. She showed marked improvement of anemia after steroid therapy with subsidence of all the clinical and laboratory manifestations of hemolysis when the patient went into remission. AlHA should be considered as one cause of anemia in de novo AML patients, and blood transfusions should be given carefully in such cases to avoid harmful hemolysis.
\end{abstract}

Keywords: Autoimmune hemolysis; Anemia; Acute leukemia

\section{Introduction}

Autoimmune hemolytic anemia (AIHA) has been described in patients with lymphoid neoplasm with an etiologic relationship between the emergence of autoantibodies and lymphocyte dysfunction [1-4]. On the other hand, autoimmune disorders are less to develop in patients with other neoplasm like chronic myeloid leukemia, myelodysplastic syndrome, acute myeloid leukemia or myeloproliferative disorders transformed to acute myelocytic leukemia [5]. Few reports have been documented the development of immune hemolytic anemia in patients with acute myeloid leukemia [5-7]. Similarly, hemolytic anemia either immune or non immune has been reported with cases of erythroleukemia [8,9].We herein, describe the development of AIHA in a patient with acute myelomonocytic leukemia.

\section{Case Report}

A 58-year-old female presented with a history of marked fatigue and bone ache with no remarkable past medical history. She did not take specific medications or receive blood products before admission. She had no clinical evidence of infection before or at the time of examination. Complete blood count at presentation showed WBC: 33 $\times 10^{9} / \mathrm{L}$ with $\mathrm{Hb}: 12.1 \mathrm{~g} / \mathrm{dL}$ and platelet count $123 \times 10^{9} / \mathrm{L}$. The differential WBCs revealed monocytosis with $15 \%$ blasts in peripheral blood. The diagnosis of acute myelomonocytic leukemia M5 was confirmed by immunophenotyping on bone marrow aspirate which revealed $45 \%$ myeloblast population positive for CD34, CD13, CD33 and $5-6 \%$ of the acquired cells were large monocyte population positive for CD14, CD64, CD36, CD11b, and CD11c. Pan CT revealed only thickening of posterior nasopharyngeal wall and enlarged both tonsils. Fundus examination was normal and CSF analysis was free.
The patient started $3 / 7$ protocol with adriamycin $30 \mathrm{mg} / \mathrm{m}^{2} \mathrm{~d} 1-3$ plus cytarabine $100 \mathrm{mg} / 12 \mathrm{~h} \mathrm{~d} 1-7$ with a hemoglobin level of $10.4 \mathrm{~g} / \mathrm{dl}$. Starting from day 4 of the cycle, the $\mathrm{Hb}$ level showed rapid and marked decrease to $6.9 \mathrm{~g} / \mathrm{dl}$. Cross matching for packed RBCs was incompatible with many units even with $\mathrm{O}$ negative blood. The chemotherapy was temporarily stopped till improvement of $\mathrm{Hb}$ level. Work up for hemolysis revealed indirect hyperbilirubinemia, reduced plasma haptoglobin [20 mg/dl ( $\mathrm{N}: 41-165 \mathrm{mg} / \mathrm{dL})]$, high LDH level [1767.13 U/L (N: 0-480 U/L)] with positive direct Coombs' test. The type of antibody could be identified as Immunoglobulin G (IgG) with monospecific antibodies. The reticulocytic count was only $0.5 \%$. Absence of reticulocytosis was explained by bone marrow infiltration by blast cells. Virology for HCV, HBV and HIV was negative. The patient started dexamethasone $10 \mathrm{mg}$ every $12 \mathrm{~h}$ with gradual improvement of $\mathrm{Hb}$ level as it reached $10.6 \mathrm{~g} / \mathrm{dl}$ when the chemotherapy started again. The patient completed the first cycle and started steroid withdrawal with stable $\mathrm{Hb}$ level. $\mathrm{Hb}$ level started to decrease again on day 18 of the cycle which could be corrected by RBCs transfusion. This decline in $\mathrm{Hb}$ level at that time was attributed to chemotherapy induced myelosupression. Evaluation of response to the first cycle of chemotherapy with bone marrow aspirate showed complete remission. However, her Hb level decreased to $7.7 \mathrm{~g} / \mathrm{dl}$ by the time of the second course of chemotherapy with incompatible RBCs for transfusion. The Coombs ' test was still positive. She received a short course of dexamethasone again and the $\mathrm{Hb}$ increased to $11 \mathrm{~g} / \mathrm{dl}$ where she could receive her second chemotherapy course. The patient continued consolidation chemotherapy with high dose cytarabine as per protocol. Her $\mathrm{Hb}$ remained stable without the need for neither transfusion nor steroids. The Coombs' test was negative when tested before receiving the treatment. Currently, the patient is stable in remission with acceptable $\mathrm{Hb}$ level without any evidence of hemolysis. 


\section{Discussion}

We herein, present the case of de novo acute myelomonocytic leukemia associated with autoimmune hemolytic anemia. The patient has no previous medical history of anemia and $\mathrm{Hb}$ level at presentation was normal. She received chemotherapy containing Adriamycin plus Cytarabine. She showed marked improvement of anemia after steroid therapy with subsidence of all the clinical and laboratory manifestations of hemolysis when the patient went into remission. Similar patients with AML with autoantibodies against erythrocytes with positive Coombs' test with or without evidence of hemolysis have been reported $[5,10,11]$. Turpin et al. reported a case of AML developed 5 years after the onset of an autoimmune hemolytic anemia. The cytological origin of the proliferation was difficult to assess. The presence of prominent membranous complexes and a strong positivity of acid phosphatase reaction favoured its megakaryocytic origin. It was not known if the two diseases were successive consequences of preexisting state of immune depression or the AML was such a state created by the autoimmune anemia [12]. Erythroleukaemia which is a rare form of acute myeloid leukemia is extremely difficult to be diagnosed on the early stage. It may make its debut under the mask of hemolytic anemia and can be acceptably suspected only after emergence of malignant cells in peripheral blood [8]. The mechanism of development of AIHA in denovo AML is unclear. Some reports postulate that an antibody was produced against a tumor antigen expressed on malignant erythroblast derived erythrocytes. However, this was ruled out in some cases because antibodies were also directed toward the normal erythrocytes. Other explanation may be related to the development of immunologic regulatory cells as suppressor T cells which allowed the development of autoimmunity [5]. In conclusion, AIHA should be considered as one cause of anemia in de novo AML patients, and blood transfusions should be given carefully in such cases to avoid harmful hemolysis.

\section{References}

1. Brady-West DC, Thame J, West W (1997) Autoimmune haemolytic anaemia, immune thrombocytopenia, and leucopenia. An unusual presentation of Hodgkin's disease. West Indian Med J 46: 95-96.
2. Piernas S, Xicoy B, Grifols JR, Ribera JM (2006) [Autoimmune hemolytic anemia with positive direct antiglobulin test associated with $\mathrm{T}$ cell acute lymphoblastic leukemia]. Med Clin (Barc) 126: 678-679.

3. Deeren D (2009) B-lymphoblastic leukaemia presenting as autoimmune haemolytic anaemia. Ann Hematol 88: 499.

4. Mainwaring CJ, Walewska R, Snowden J, Winfield DA, Ng JP, et al. (2000) Fatal cold anti-i autoimmune haemolytic anaemia complicating hairy cell leukaemia. Br J Haematol 109: 641-643.

5. Tamura H, Ogata K, Yokose N, An E, Kamikubo K, et al. (1996) Autoimmune hemolytic anemia in patients with de novo acute myelocytic leukemia. Ann Hematol 72: 45-47.

6. Renoux M, Bernard JF, Vroclans M, Dhermy D, Boivin P (1978) [Evans' syndrome during acute myelomonocytic leukemia. 2 cases]. Sem Hop 54: 805-808.

7. Mangal AK, Buskard NA (1984) Acute myeloblastic leukaemia and autoimmune haemolytic anaemia. Clin Lab Haematol 6: 89-91.

8. Kvezereli-Kopadze A, Mtvarelidze Z, Kvezereli-Kopadze M (2008) [Autoimmune haemolytic anaemia - as a mask of acute erythroleukaemia]. Georgian Med News: 43-47.

9. Gupta A, Sinha S, Aggarwal S, Bhargava M (2014) Erythroleukemia Presenting as Non-immune Haemolytic Anemia: A Rare Presentation. Indian J Hematol Blood Transfus 30: 219-222.

10. Meloni G, Andrizzi C, Vignetti M, Girelli G, Mandelli F (1995) Autoimmune hemolytic anemia in a patient with acute myelogenous leukemia treated with low-dose interleukin-2 after autologous bone marrow transplantation. Blood 86: 837-838.

11. Deutsch M, Dourakis SP, Papanikolopoulos K, Belegrati M, Kalmantis T (2003) Autoimmune hemolytic anemia in a patient with acute myelocytic leukemia. Am J Hematol 74: 147.

12. Turpin F, Lejeune F, Lortholary P (1980) [Autoimmune hemolytic anemia anemia followed by acute granulocytic leukemia (author's transl)]. Pathol Biol (Paris) 28: 305-311. 